\title{
Hand Hygiene Compliance in an Education and Research Hospital Intensive Care Units
}

\author{
Ilkay Bahceci (Corresponding author) \\ Recep Tayyip Erdogan University, Faculty of Medicine \\ Department of Medical Microbiology, Rize, Turkey \\ E-mail:ilkay.bahceci@erdogan.edu.tr \\ Ilknur Esen Yildiz \\ Recep Tayyip Erdogan University, Faculty of Medicine, \\ Department of Infectious Diseases, Rize, Turkey \\ E-mail:ilknuresen.yildiz@erdogan.edu.tr \\ Yunus Emre Ibik \\ Recep Tayyip Erdogan University, Faculty of Medicine \\ Department of Medical Microbiology, Rize, Turkey \\ E-mail:yunusemre.ibik@erdogan.edu.tr \\ Leyla Kazancioglu \\ Recep Tayyip Erdogan University, Faculty of Medicine, \\ Department of Anesthesiology and Reanimation, Rize, Turkey \\ E-mail:leyla.kazanc1oglu@erdogan.edu.tr \\ Sule Batcik \\ Recep Tayyip Erdogan University, Faculty of Medicine, \\ Department of Anesthesiology and Reanimation, Rize, Turkey \\ E-mail:sule.batc1k@erdogan.edu.tr
}

\begin{abstract}
Objective and Aim:

Errors occurring during the provision of health services are medical errors. Hospital infections counted among these errors remain a serious health problem on the agenda. Hand hygiene is the most effective and cheapest way to prevent hospital infections, and it is also a method that can be easily applied by the healthcare worker. With hand hygiene compliance, it has been shown that one third of the hospital infections and even one third and half of the hospital infections occurring in intensive care are reduced. In this study, it was aimed to evaluate hand hygiene observation data retrospectively in intensive care units.
\end{abstract}

\section{Materials and Method:}

This study was carried out in Recep Tayyip Erdoğan University (RTEU) Training and Research Hospital Intensive Care Units (Internal Intensive Care, Surgical Intensive Care, Anesthesia Intensive Care, Cardiovascular Surgery Intensive Care, Coronary Intensive Care, Pediatric Intensive Care, Newborn Intensive Care) in 2016 and 2017. There were doctors, nurses and assistant health personnel among the healthcare professionals. Hand hygiene observation was made according to five basic indication rules.

\section{Results:}

In the Intensive Care Units (ICU), 255 health workers were evaluated in 2016 and 430 in 2017. The compliance rate in the ICU was evaluated as $86 \%$. According to the five indication rules, the highest compliance was with $90-95 \%$ before aseptic procedures, after contamination with body fluids and after contact with the patient's environment. The least compliance was before contact with $60 \%$ of patients. According to professions, the compliance rate of physicians was $85 \%$, nurses $95 \%$, and assistant health personnel $90 \%$. According to the units; The highest compliance was in the Surgical Intensive Care, 
Pediatrics and Neonatal Intensive Care Unit with 97\%, and the least in the Anesthesia and Internal Medicine Intensive Care Units with $69 \%$ and $60 \%$

\section{Discussion and Conclusion:}

Hand hygiene compliance; It is still below the desired levels, with regular training, evaluations and feedback. Hospital infections, especially for the prevention of intensive care infections, besides continuing education, rewarding practices will be more motivating for healthcare professionals here. It should develop and implement a feasible, acceptable, acceptable hand hygiene policy in hospitals.

Keywords: Hand hygiene compliance, feedback, patient safety, intensive care

DOI: $10.7176 / \mathrm{JHMN} / 75-02$

\section{Bir Eğitim ve Araştırma Hastanesi Yoğun Bakım Ünitelerindeki El Hijyeni Uyumu}

\section{Uluslararası Sterilizasyon Dezenfeksiyon Kongresinde poster bildirisi olarak sunulmuştur.}

\section{Özet}

Giriş ve Amaç:

Sağlık hizmetleri sunumu sırasında oluşan hatalar tıbbi hatadır. Bu hatalar içinde sayılan hastane enfeksiyonları oldukça ciddi bir sağlık problemi olarak gündemdeki yerini korumaktadır. El hijyeni hastane enfeksiyonlarının önlenmesinde en etkili ve en ucuz yol olduğu gibi sağlık çalışanı tarafından da kolaylıkla uygulanabilir bir yöntemdir. El hijyeni uyumu ile hastane enfeksiyonlarının üçte birinin hatta yoğun bakımda meydana gelen hastane enfeksiyonlarının üçte biri ile yarısının azaldığı gösterilmiştir. $\mathrm{Bu}$ çalışmada yoğun bakım ünitelerinde el hijyeni gözlem verilerinin retrospektif olarak değerlendirilmesi amaçlanmıştır.

\section{Yöntem:}

Bu çalışma 2016 ve 2017 yıllarında Recep Tayyip Erdoğan Üniversitesi (RTEÜ) Eğitim ve Araştırma Hastanesi Yoğun Bakım Ünitelerinde ( Dahili Yoğun Bakım, Cerrahi Yoğun Bakım, Anestezi Yoğun Bakım, Kalb- Damar Cerrahi Yoğun Bakım, Koroner Yoğun Bakım, Pediatrik Yoğun Bakım, Yeni Doğan Yoğun Bakım) yapıldı. Sağlık çalışanları içinde doktor, hemşire, yardımcı sağlık personeli mevcuttu. El hijyeni gözlemi beş temel endikasyon kuralına göre haberli olarak yapıldı.

\section{Bulgular:}

Yoğun Bakım Ünitelerinde ( YBÜ) 2016 yılında 255, 2017 yılında 430 sağlık çalışanı değerlendirildi. YBÜ 'de uyum oranı \% 86 olarak değerlendirildi. Beş endikasyon kuralına göre en yüksek uyum \% 9095 ile aseptik işlemlerden önce, vücut sıvılarıyla bulaştan sonra ve hasta çevresiyle temastan sonra idi. En az uyum ise \% 60 hasta ile temas öncesindeydi. Mesleklere göre ise doktorların uyum oranı \% 85, hemşirelerin \% 95, yardımcı sağlık personelininki \% 90 civarındaydı. Ünitelerin göre; en yüksek Cerrahi Yoğun Bakım, Pediatri ve Yeni Doğan Yoğun Bakım Ünitesinde \% 97 en az uyum ise \% 69 ile Anestezi ve Dahiliye Yoğun Bakım Ünitelerinde idi.

\section{Tartışma ve Sonuç:}

El hijyeni uyumu; düzenli eğitim, değerlendirmeler ve geri bildirimle beraber hala istenilen düzeylerin altındadır. Hastane enfeksiyonları özelliklede yoğun bakım enfeksiyonlarının önlenmesinde sürekli eğitim yanında ödüllendirici uygulamalar buradaki sağlık çalışanları açısından daha motive edici olacaktır. Hastanelerde uygulanabilir, özümsenebilir, kabul edilebilir bir el hijyeni politikası geliştirmeli ve uygulanabilmelidir.

Anahtar Kelimeler: El hijyeni uyumu, geri bildirim, hasta güvenliği, yoğun bakım 


\section{Giriş}

Hasta ve hastane hizmetlerindeki önemli gelişmelere karşın hastane enfeksiyonları hem uluslararası hem de ulusal düzeyde önemli bir problem olarak karşımıza çıkmaktadır. Hastane enfeksiyonları hastaların morbidite ve mortalitesinde artışa yol açmaktadır. Ayrıca hastane de kalış süresinin uzaması, iş kaybının ortaya çıkması, ilaç kullanımının artması özellikle antibiyotik kullanımı ve buna bağlı direnç gelişimi, fazladan tanı yöntemlerinin kullanımı ve bakım maliyetlerinin artması ekonomik yükü de artırmaktadır (1). Sağlık çalışanlarının elleri, hastane enfeksiyonlarının aktarımında en önemli yoldur ve bu nedenle de el hijyeni hastane enfeksiyonlarının önlenmesinde en etkin yöntemdir (2,3). El hijyeninde beş endikasyon kuralına uyum ile hastane enfeksiyonlarında yaklaşık \%30- 50 oranında düşme olduğu belirtilmektedir (4-5). Dünya Sağlık Örgütü (DSÖ) tarafından yayınlanan kılavuzlar hastane enfeksiyonlarının önlenmesinde el yıkamayı basit ama etkili bir uygulama olarak yaygın bir şekilde tavsiye etmekte ve kullanımını desteklenmektedir. Bütün bunlara karşın tüm dünyadaki çalışmalar el yıkama uyumluluk oranının olması gerekenden fazlasıyla düşük seviyelerde olduğu göstermektedir (67). Sağlık çalışanlarında el hijyenine uyumu gözlemlemek ve buna ait bildirimlerde bulunmak el hijyenine uyumu artırıcı rol oynamaktadır (8). DSÖ tarafından hala en etkin standart olarak belirlenen yöntem el hijyenine uyumu direk olarak gözlemleyip buna ait geri bildirimlerde bulunmaktır. DSÖ el yıkamada beş endikasyon belirlemiştir. Bunlar; hastaya temas etmeden önce, aseptik işlemlerden önce, vücut sıvılarının bulaşma riski sonrası, hastaya temas ettikten sonra, hasta çevresine temas ettikten sonra ellerin yıkanması şeklindedir (2). Hastane bünyesinde el hijyenine uyumun en önemli olduğu ünitelerden biri kuşkusuz yoğun bakımlardır. Çünkü hastane enfeksiyonları ve kritik hastaların en fazla olduğu, invaziv işlemlerin yapıldığ 1 , mekanik ventilasyonun kullanıldığı, çoklu mikroorganizma enfeksiyonları ve antibiyotik direncinin olduğu ve salgınların yaşanabileceği birimlerdir(9). Bundan dolayıdır ki el hijyeni uyumu bu ünitelerde çalışan sağlık personeli için daha da önemlidir. Bu çalışmada farklı yoğun bakım ünitelerinde çalışan personel için el hijyeni uyum oranının saptamayı amaçlanmıştır.

\section{Yöntem:}

Bu çalışma 2016 ve 2017 yıllarında Recep Tayyip Erdoğan Üniversitesi (RTEÜ) Tıp Fakültesi Eğitim ve Araştırma Hastanesi Yoğun Bakım Ünitelerinde ( Dahili Yoğun Bakım Ünitesi (DYBÜ), Cerrahi Yoğun Bakım Ünitesi (CYBÜ), Anestezi Yoğun Bakım Ünitesi (AYBÜ), Kalb- Damar Cerrahisi Yoğun Bakım Ünitesi (KDCYBÜ), Koroner Yoğun Bakım Ünitesi (KYBÜ), Pediatrik Yoğun Bakım Ünitesi (PYBÜ), Yeni Doğan Yoğun Bakım Ünitesi (YDYBÜ) ) retrospektif olarak gerçekleştirildi. Sağlık çalışanları içinde doktor, hemşire, yardımcı sağlık personeli mevcuttu. El hijyeni gözlemi beş temel endikasyon kuralına göre saat 09:00 - 16: 00 arasında haberli olarak yapıldı. Kullanılan el hijyeni gözlem formu DSÖ önerileri doğrultusunda Sağlık Bakanlığının Kalite ve Akreditasyon Daire başkanlığınca hazırlanan ve hastanemiz Enfeksiyon Kontrol Komitesi tarafından sürveyan verilerini kaydetmek için kullandığı formdu. Hastanemizde 2011 yılından itibaren el hijyeni adına düzenli hizmet içi eğitimler, değerlendirmeler ve haberli el hijyeni gözlemi yapılmaktadır. Çalışmada kullanılan veriler için Hastanemiz Başhekimliğinden izin alındı. Toplanan veriler SPSS 21.0 paket programında analiz edildi. Verilerin değerlendirilmesinde sayı (n) ve \% kullanıldı.

\section{Bulgular:}

Yoğun Bakım Ünitelerinde ( YBÜ) 2016 yılında 255, 2017 yılında 430 sağlık çalışanı değerlendirildi. YBÜ 'de el hijyeni uyum oranı genel olarak \% 86 olarak saptandı. Beş endikasyon kuralına göre en yüksek uyum oranı "'aseptik işlemlerden önce", "vücut sıvılarıyla bulaş riski sonrası"' ve "hasta çevresiyle temastan sonra" yaklaşık \% 90-95 arasındaydı. En düşük uyum ise "'hasta ile temas öncesinde", olmak üzere \% 60 civarındaydı. Mesleklere göre el hijyeni uyumu değerlendirildiğin de doktorların uyum oranı \% 85, hemşirelerin \% 95, yardımcı sağlık personelininki $\% 90$ civarındaydı. Ünitelerin çeşitliliğine göre el hijyeni uyumu; en yüksek Cerrahi Yoğun Bakım ve Pediatri Yoğun Bakım, Yeni Doğan Yoğun Bakım Ünitesinde \% 97 en az uyum ise \% 69 ile Anestezi Yoğun Bakım ve \% 60 ile Dahiliye Yoğun Bakım Ünitelerinde idi. Grafik 1 'de mesleklere göre el hijyeni uyum oranı verildi. Grafik 2' de Yoğun Bakım Ünitelerine göre el hijyeni uyum oranı verildi. Tablo 1 ' de ise El hijyeni uyumunun beş endikasyon kuralına göre yoğun bakım ünitelerindeki oranları verilmiştir. 

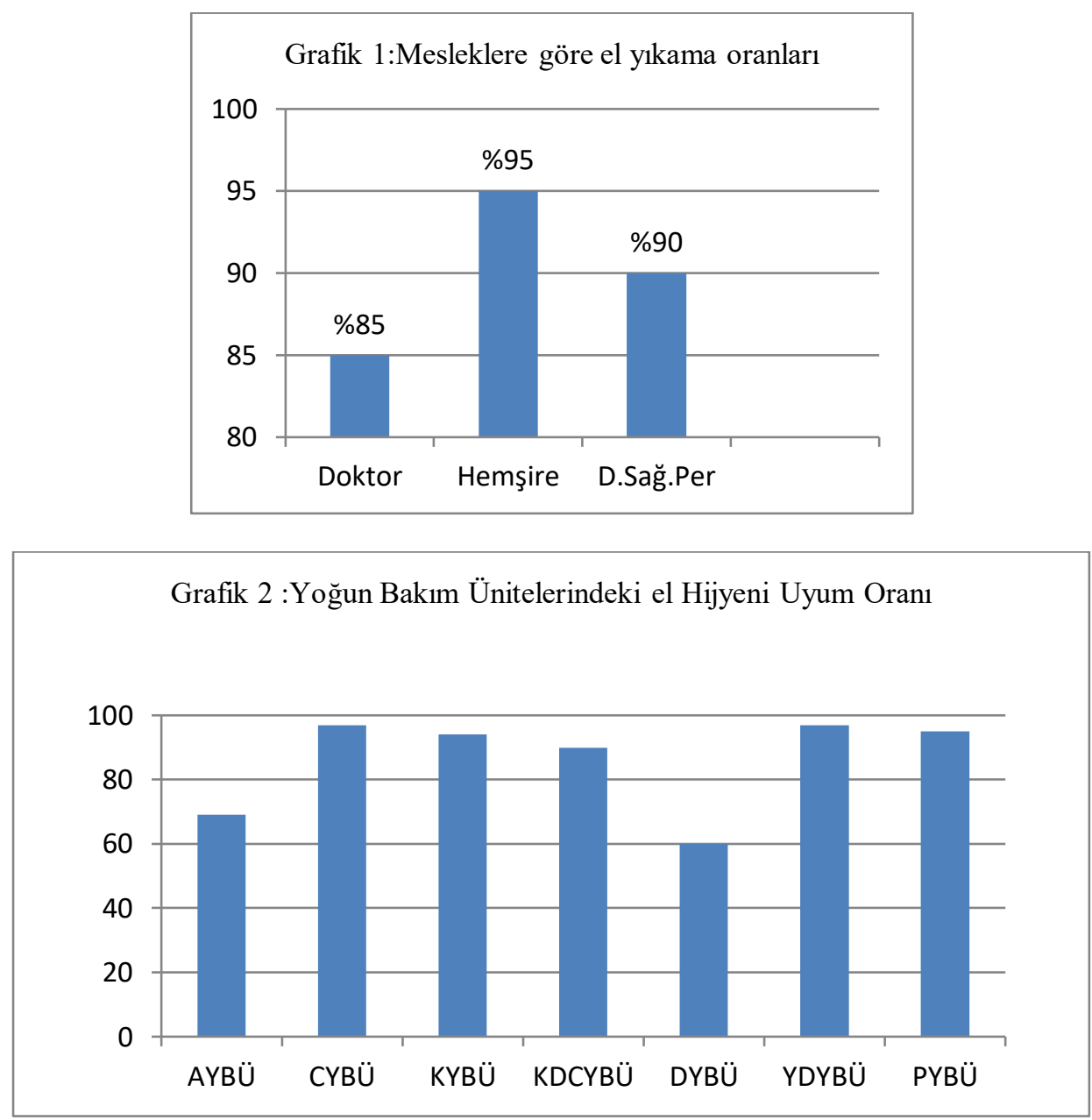

Tablo: 1 El hijyeni uyumunun beş endikasyon kuralına göre yoğun bakım ünitelerindeki el yıkama oranlar1

\begin{tabular}{|l|}
\hline $\begin{array}{l}\text { Üniteler/El } \\
\text { hijyenindeki beş } \\
\text { endikasyon }\end{array}$ \\
\hline $\begin{array}{l}\text { Hastaya temastan } \\
\text { önce/El yıkama var }\end{array}$ \\
\hline $\begin{array}{l}\text { Aseptik işlemlerden } \\
\text { önce/EI yıkama var }\end{array}$ \\
\hline $\begin{array}{l}\text { Vucüt sıvılarıla } \\
\text { bulaş riski sonrası } \\
\text { /El yıkama var }\end{array}$ \\
\hline $\begin{array}{l}\text { Hastaya temastan } \\
\text { sonrası/EI yıkama } \\
\text { var }\end{array}$ \\
\hline $\begin{array}{l}\text { Hasta çevresiyle } \\
\text { temas sonrası /EI } \\
\text { yıkama var }\end{array}$ \\
\hline
\end{tabular}

\begin{tabular}{|c|c|c|c|c|c|c|c|}
\hline AYBÜ & CYBÜ & KYBÜ & KDCYBÜ & DYBÜ & YDYBÜ & PYBÜ & Toplam \\
\hline $\begin{array}{c}42 \\
\% 50\end{array}$ & $\begin{array}{c}112 \\
\% 70\end{array}$ & $\begin{array}{c}48 \\
\% 60\end{array}$ & $\begin{array}{c}28 \\
\% 70\end{array}$ & $\begin{array}{c}84 \\
\% 42\end{array}$ & $\begin{array}{c}30 \\
\% 75\end{array}$ & $\begin{array}{c}45 \\
\% 56\end{array}$ & $\begin{array}{c}389 \\
\% 60\end{array}$ \\
\hline $\begin{array}{c}66 \\
\% 78\end{array}$ & $\begin{array}{l}152 \\
\% 95\end{array}$ & $\begin{array}{c}68 \\
\% 85\end{array}$ & $\begin{array}{c}39 \\
\% 98\end{array}$ & $\begin{array}{c}134 \\
\% 67\end{array}$ & $\begin{array}{c}38 \\
\% 96\end{array}$ & $\begin{array}{c}61 \\
\% 76\end{array}$ & $\begin{array}{c}558 \\
\% 85\end{array}$ \\
\hline $\begin{array}{c}81 \\
\% 95\end{array}$ & $\begin{array}{c}160 \\
\% 100\end{array}$ & $\begin{array}{c}79 \\
\% 98\end{array}$ & $\begin{array}{c}39 \\
\% 98\end{array}$ & $\begin{array}{c}168 \\
\% 80\end{array}$ & $\begin{array}{c}40 \\
\% 100\end{array}$ & $\begin{array}{c}75 \\
\% 94\end{array}$ & $\begin{array}{l}642 \\
\% 95\end{array}$ \\
\hline $\begin{array}{c}72 \\
\% 85\end{array}$ & $\begin{array}{c}157 \\
\% 98\end{array}$ & $\begin{array}{c}77 \\
\% 96\end{array}$ & $\begin{array}{c}38 \\
\% 94\end{array}$ & $\begin{array}{l}160 \\
\% 80\end{array}$ & $\begin{array}{c}38 \\
\% 96\end{array}$ & $\begin{array}{c}65 \\
\% 81\end{array}$ & $\begin{array}{c}607 \\
\% 90\end{array}$ \\
\hline $\begin{array}{c}72 \\
\% 85\end{array}$ & $\begin{array}{c}157 \\
\% 98\end{array}$ & $\begin{array}{c}76 \\
\% 95\end{array}$ & $\begin{array}{c}36 \\
\% 90\end{array}$ & $\begin{array}{c}160 \\
\% 80\end{array}$ & $\begin{array}{c}40 \\
\% 100\end{array}$ & $\begin{array}{c}76 \\
\% 95\end{array}$ & $\begin{array}{c}642 \\
\% 95\end{array}$ \\
\hline
\end{tabular}




\section{Tartışma ve Sonuç:}

Günümüzde hasta güvenliği ve dolasıyla hastane enfeksiyonları ile ilgili sorunlarda kurum ve sağlık çalışanları odak noktası olma özelliğini sürdürmektedir (10). Durum böyle iken hastane enfeksiyonlarının önlenmesine yönelik sağlık personeli el hijyeni gözden geçirildiğinde uyumun hala çok düşük seviyelerde olduğu görülmektedir (11). Özellikle invaziv işlemlerin yapılması, immun suprese ve eşlik eden komorbid durumu olan hastaların yatması, sürekli hizmetin verilmesi, yoğun bakım ünitelerini özellikli birimler durumuna getirmiştir. Bundan dolayıdır ki hastane enfeksiyonları açısından daha riskli ünite olarak kabul edilen yoğun bakım ünitelerinde enfeksiyonları önlemek, mortaliteyi azaltmak ve hastanın yaşam kalitesini artırmak için el hijyeni uyumu en yüksek seviyede olmalıdır (12). Terzi ve arkadaşları yaptığı çalışmada karma yoğun bakım ünitelerinde el hijyeni uyum oranını \% 55,5 olarak saptamışlardır ( 7). Sili ve arkadaşlarının ülkemizde yaptığı başka bir çalışmada ise el hijyeni uyum oranı \% 40,6 olarak tespit edilmiştir (13). Karabay ve arkadaşlarının Yeni Doğan Yoğun Bakım Ünitesinde yaptıkları çalışmada el hijyeni uyumu \% 49 olarak saptanmıştır (14). Bence ve arkadaşları anestezi yoğun bakım ünitesinde yaptığı çalışmada el hijyeni uyum oranını \% 86,5 olarak saptamıştır (15). Yaptığımız çalışmada genel olarak yoğun bakım ünitelerinde el hijyeni uyum oranı yaklaşık \% 86 olarak saptanmıştır. Çalışmalar arasındaki bu farklılık ve hastanemizdeki oranın yüksek çıkması 2011 yılından itibaren el hijyeni eğitimlerin düzenli yapılmasına, farkındalığın artırılmasına yönelik çalışmanın etkili olmasına ve olumlu geri bildirimlere bağlı olabilir.

Beş endikasyon kuralına göre el hijyeni uyumu gözden geçirildiğinde Makay ve arkadaşlarının yaptıkları çalışmada en yüksek oran \% 34 ile ' aseptik işlem sonrası eldiven çıkarıldıktan sonra" en düşük uyum ise \% 12 ile "hastayla temasın olduğu yara bakımı sonrası" gerçekleşmiştir. Genel ortalama ise \% 23 saptanmıştır ( 16). Ülkemizde yapılan başka bir çalışmada beş endikasyon kuralına göre en yüksek el hijyeni uyumu yine 'aseptik işlemlerden sonra' \% 36,5 en düşük uyum ise \% 9,3 ile " aseptik işlem öncesi'" saptanmıştır (7). Yine ülkemizde yoğun bakım ünitelerinde yapılan başka bir çalışmada ise en yüksek oran \% 68,6 ile ' 'hasta ile temas sonrası', en düşük oran ise \% 21,7 ile "'aseptik işlemlerden önce" olmak üzere tespit edilmiştir (13). Albert ve arkadaşlarının yaptığı bir eğitim çalışması sırasında el hijyeni uyum oranı ' 'hastaya temas öncesi ve sonrası" \% 93 olmak üzere genel ortalamada \% 93 olarak saptanmıştır (17). Alshehari ve arkadaşlarının yaptı̆̆ hijyen uyumunu genel olarak hepsinde \%51,5 olarak tespit edildiği gibi çalışanlara eğitim verdikten sonra bile hiçbir endikasyonda \% 100 olarak saptayamamışlardır (18). Bizim çalışmamızda ise beş endikasyon kuralına göre en yüksek uyum oranı yaklaşı \% 90-95 ile ''aseptik işlemlerden önce', "vücut sıvılarıyla bulaştan sonra" ve "hasta çevresiyle temastan sonra" idi. En düşük uyum ise yaklaşı1k \% 60 ile ' 'hasta ile temas öncesinde'" saptand1.

Meslek gruplarına göre el hijyeni uyum oranları, yoğun bakım ünitelerinde gözden geçirildiğinde ülkemizde yapılan çalışmalarda sırasıyla \% 34 hemşireler, \% 19 yardımcı sağlık personeli \% 12 ile hekimler şeklindedir (16). Yine ülkemizde yapılan başka bir çalışmada sırasıyla en yüksek el hijyeni uyumu \% 75,5 ile hemşireler, \% 56,5 ile hekimler \% 55 ile diğer sağlık personeli şeklinde gerçekleşmiştir (13). Hoffmann ve arkadaşlarının yaptığı bir çalışma da sırasıyla en yüksek uyumun \% 80,2 ile hemşirelerde, \% 61,3 ile diğer sağlık çalışanlarında ve \% 61,2 ile hekimlerde olduğu saptanmıştır (19). Baek ve arkadaşlarının yaptığı bir çalışmada ise en düşük uyum oranı \% 30 ile hekimlerde saptanmıştır (20). Mogyorodi ve arkadaşlarının yaptığı bir çalışmada ise hemşirelerdeki uyum \%62,9 olurken hekimlerdeki uyum \% 53,9’ da kalmıştır (21). Bizim çalışmamızda ise ülkemiz ve dünyadaki çalışmalara benzer şekilde sırasıyla el hijyen uyum oranları \% 95 hemşireler, \% 90 diğer sağlık personeli, $\% 85$ hekimler şeklinde gerçekleşmiştir.

Sili ve arkadaşlarının yaptığı çalışmada Cerrahi Yoğun Bakım Ünitelerdeki uyum Dahili Yoğun Bakım Ünitelerinden yüksek bulunmuştur (13). Stahmeyer ve arkadaşlarının yaptığı kapsamlı bir çalışmada ortalama el hijyen uyum oranı \% 42 olarak saptanmakla birlikte Cerrahi Yoğun Bakım Ünitelerindeki uyum Dahili Yoğun Bakım Ünitelerinden yüksek olarak saptanmıştır (22). Bizim çalışmamızda yoğun bakım üniteleri içinde en yüksek uyum \% 97 ile Cerrahi Yoğun Bakım, Pediatri ve Yeni Doğan Yoğun Bakım Ünitesinde, en az uyum ise \% 69 ile Anestezi ve \% 60 ile Dahiliye Yoğun Bakım Ünitelerinde gerçekleşmiştir.

Sonuç olarak; Hastanemizde el hijyeni uyumu genel olarak ülkemiz ortalamasına göre yüksek olsa bile yinede hedef değerin altındadır. El hijyeni uyumu; düzenli eğitim, düzenli değerlendirmeler ve geri bildirimle beraber hala istenilen düzeylerde olmasa da uyum oranlarını artıran en önemli faktör çalışanların ( direk, kamera, video yöntemiyle) izlenmesi ve devamında acil geri bildirimlerin hemen yapılmasıdır. Hastane enfeksiyonları özellikle de yoğun bakım enfeksiyonlarının önlenmesinde ünitelerin haberli-habersiz gözlenmesi yanında ödüllendirici uygulamalar buradaki sağlık çalışanları açısından daha da motive edici olacaktır. El hijyeni uyumu hekimlerde diğer meslek gruplarına göre daha

13 | P a g e 
düşük olduğundan hekimlere yönelik Tıp Fakültesi eğitimi sürecinde ders olarak programlarına yerleştirilmeli ve bununla ilgili pratik beceri eğitimleri bu dönemde verilmelidir. Hastanelerde Kalite Birimi ile Enfeksiyon Kontrol Komitesi birlikte çalışarak özümsenebilir, kabul edilebilir bir el hijyeni politikası geliştirmeli ve uygulamasını sağlamalıdır.

$\mathrm{Bu}$ yazıdaki hiçbir yazarın herhangi bir çıkar çatışması yoktur. Yazının herhangi bir finansal desteği yoktur.

10. Uluslararası Sterilizasyon Dezenfeksiyon Kongresinde poster bildirisi olarak sunulmuştur.

\section{Kaynaklar:}

1. Gould DJ, Creedon S, Jeanes A, Drey NS, Chudleigh J, Moralejo D. Impact of observing hand hygiene in practice and research: a methodological reconsideration. Journal of Hospital Infection 2017;95: 169-74

2. WHO Guidelines on Hand Hygiene in Health Care [İnternet]. Geneva: World Health Organization WHO/CED/PHE/WSH/2019.149

3. Özată̆ D. M. Cerrahi El Antisepsisi; Nereye Gidiyoruz? 11. Uluslararası Sterilizasyon Dezenfeksiyon Kongresi, 27 Kasım-1 Aralık 2019 Antalya. Kongre kitabı, s:66-72

4. Çoksak A, Çelik Y, Danacı C, Sökel S. Yoğun bakım ünitelerinde invaziv uygulamalar ve enfeksiyon ilişkisi. MAKÜ Sag Bil Enst Derg 2017;5: 22-31.

5. Rosenthal VD, Maki DG, Salomao R, Moreno CA, Mehta Y, Higuera F, et al; International Nosocomial Infection Control Consortium. Device-Associated Nosocomial İnfections in 55 İntensive Care Units of 8 Developing Countries. Ann Intern Med 2006;145:582-91

6. Chatfield SL, Nolan R, Crawford H, Hallam JS. Acute care nurses' responses and recommendations for improvement of hand hygiene compliance: A crosssectional factorial survey research study. Am J Infect Control 2017;45: 620-5.

7. Terzi B, Erdoğan H, Ertürk M, Özkan S.C., Investigation of Hand Washing Behaviors in Intensive Care Units. Turk J Intensive Care 2020;18: 6-12

8. Boyce JM. Hand hygiene compliance monitoring: current perspectives from the USA. Journal of Hospital Infection. 2008; 70: 2-7.

9. Erasmus V, Daha TJ, Brug H. Systematic review of studies on compliance with hand hygiene guidelines in hospital care. Infect Control Hosp Epidemiol. 2010; 31(3): 283-294.

10. Palteki T, Sur H, Yazici G, Şimşek E.E,, Baktır Y. Evaluation of the Patients' Attitudes and Behaviors Concerning Patient Safety. SCIE. 2020; 31(1): 69-74

11. World Health Organization. Guidelines on hand hygiene in health care. Geneva: WHO; 2009. Last Accessed Date: 24.10.2018.

12. Battistella G, Berto G, Bazzo S. Developing professional habits of hand hygiene in intensive care settings: An action-research intervention. Intensive Crit Care Nurs 2017;38: 53-9.

13. Sili U, Ay P, Bilgin H, Hidiroğlu S, Korten V., Hand hygiene knowledge, perception and practice of healthcare workers in a Turkish university hospital intensive care unit. J Infect Dev Ctries 2019; 13(8):744-747

14. Karabay M, Kaya G, Hafizoğlu T Karabay O, Effect of camera monitoring and feedback along with training on hospital infection rate in a neonatal intensive care unit. Ann Clin Microbiol Antimicrob. 2019; 18: 35 
15. Bence M, Marcell S, Erzsébet D., et al. Implementation of immediate feedback system into hand hygiene practice in the intensive care unit. Orv Hetil. 2019; 160(49): 1957-1962

16. Makay Ö, İçöz G, Yılmaz A, Kolcu F. Yoğun bakım çalışanlarının el yıkama alışkanlıkları. Ulus Travma Acil Cerrahi Derg 2008;14: 149-53.

17. Albert B.D, Petti C, Caraglia A, et al, Multidisciplinary Quality Improvement Intervention to Achieve Sustained Improvement in Hand Hygiene Reliability in a Pediatric Intensive Care Unit. Pediatr Qual Saf. 2019 Nov-Dec

18. Alshehari AA, Park S, Rashid H, Strategies to improve hand hygiene compliance among healthcare workers in adult intensive care units: a mini systematic review, J Hosp Infect. 2018 Oct;100 (2):152-158

19. Hoffmann M, Sendhofer G, Gombotz V, et al, Hand hygiene compliance in intensive care units: An observational study. Int J Nurs Pract. 2020 Apr; 26(2):e12789

20. Baek A.H, Kim SE, Kim DH, et al, The difference in hand hygiene compliance rate between unit-based observers and trained observers for World Health Organization checklist and optimal hand hygiene. Int J Infect Dis. 2020 Jan; 90:197-200

21. Mogyorodi B, Szabo M, Dunai E, et al, [Implementation of immediate feedback system into hand hygiene practice in the intensive care unit, Orv Hetil. 2019 Dec;160(49):1957-1962

22. Stahmeyer JT, Lutze B, Von Lengerge T, Chaberny IF, Krauth C, Hand hygiene in intensive care units: a matter of time?, J Hosp Infect. 2017 Apr; 95(4):338-343 